\title{
Erratum to: Genetic associations in diabetic nephropathy: a meta-analysis
}

\author{
A. L. Mooyaart • E. J. J. Valk • L. A. van Es • \\ J. A. Bruijn • E. de Heer • B. I. Freedman • \\ O. M. Dekkers • H. J. Baelde
}

Published online: 11 December 2013

(C) Springer-Verlag Berlin Heidelberg 2013

\section{Erratum to: Diabetologia}

\section{DOI 10.1007/s00125-010-1996-1}

In Table 1, Fig. 2a and Fig. 3a, the minor allele of the single nucleotide polymorphism rs1617640 in the EPO promoter was incorrectly stated as being the $\mathrm{T}$ allele, whereas it should have been the $\mathrm{G}$ allele. This change does not affect the values reported and the authors apologise for any confusion this may have caused.

The online version of the original article can be found at http://dx.doi.org/ 10.1007/s00125-010-1996-1.

A. L. Mooyaart $(\bowtie) \cdot$ E. J. J. Valk · L. A. van Es · J. A. Bruijn ·

E. de Heer $\cdot$ H. J. Baelde

Department of Pathology, Bldg.1, L1-Q,

Leiden University Medical Center,

PO Box 9600, 2300 RC Leiden, the Netherlands

e-mail: a.1.mooyaart@lumc.nl

L. A. van Es

Department of Nephrology, Leiden University Medical Center,

Leiden, the Netherlands

B. I. Freedman

Section on Nephrology, Department of Internal Medicine,

Wake Forest University School of Medicine,

Winston-Salem, NC, USA

O. M. Dekkers

Department of Clinical Epidemiology,

Leiden University Medical Center,

Leiden, the Netherlands

O. M. Dekkers

Department of Endocrinology, Leiden University Medical Center,

Leiden, the Netherlands 